\title{
X-ray diagnostics of dodecane jet in spray A conditions using the new one shot engine (NOSE)
}

\author{
Ibrahim Chiboub", Hugo Ajrouche*2, Ob Nilaphai ${ }^{2}$, Sébastien Dozias ${ }^{1}$, Bruno Moreau², \\ Camille Hespel $^{2}$, Fabrice Foucher ${ }^{2}$, Christine Mounaïm-Rousselle², Jean-Michel Pouvesle ${ }^{1}$, \\ Eric Robert ${ }^{1}$ \\ 1'GREMI, CNRS-Université d'Orléans, Orléans, France \\ ${ }^{2}$ PRISME, Université d'Orléans, Orléans, France \\ *Corresponding author: hassan.ajrouche@univ-orleans.fr
}

\begin{abstract}
Quantifying liquid mass distribution data in the dense near nozzle area to develop and optimize diesel spray by optical diagnostic is challenging. Optical methods, while providing valuable information, have intrinsic limitations due to the strong scattering of visible light at gas-liquid boundaries. Because of the high density of the droplets near the nozzle, most optical methods are ineffective in this area and prevent the acquisition of reliable quantitative data. $\mathrm{X}$-ray diagnostics offer a solution to this issue, since the main interaction between the fuel and the X-rays is absorption, rather than scattering, thus $X$-ray technique offers an appealing alternative to optical techniques for studying fuel sprays. Over the last decade, $x$-ray radiography experiments have demonstrated the ability to perform quantitative measurements in complex sprays. In the present work, an X-ray technique based on X-ray absorption has been conducted to perform measurements in dodecane fuel spray injected from a single-hole nozzle at high injection pressure and high temperature. The working fluid has been doped with DPX 9 containing a Cerium additive, which acts as a contrast agent. The first step of this work was to address the effect of this dopant, which increases the sensitivity of X-ray diagnostics due its strong photon absorption, on the behavior and the physical characteristics of $n$-dodecane spray. Comparisons of the diffused back illumination images acquired from $n$ dodecane spray with and without DPX 9 under similar operating conditions show several significant differences. The current data show clearly that the liquid penetration length is different when DPX 9 is mixed with dodecane. To address this problem, the dodecane was doped with a several quantities of DPX containing $25 \% \pm 0.5$ of Cerium. Experiments show that $1.25 \%$ of Ce doesn't affect the behaviour of spray. Radiography and density measurements at ambient pressure and 60 bars are presented. Spray cone angle around $5^{\circ}$ is obtained. The obtained data shows that the result is a compromise between the concentration of dopant for which the physical characteristics of the spray do not change and the visualization of the jet by X-ray for this concentration.
\end{abstract}

\section{Keywords}

Diesel Spray, Engine, X-ray radiography, high pressure high temperature chamber, dodecane, Cerium, spray diagnostics

\section{Introduction}

New One Shot Engine (NOSE) has been designed to simulate the thermodynamic conditions at High PressureHigh Temperature (HPHT) like an actual common-rail diesel engine to study the diesel spray and combustion. The first objective was to share the experimental results required by Engine Combustion Network (https://ecn.sandia.gov). In a first step, the penetration lengths for the vapor and liquid spray at the non-reactive standard Spray-A condition ( $900 \mathrm{~K}, 60 \mathrm{bar}$, and $22.8 \mathrm{~kg} / \mathrm{m}^{3}$ with pure nitrogen) were achieved from focused shadowgraphy and diffused-back illumination (DBI) [1]. A detailed understanding of the mixing between fuel and air can lead to more efficient combustion. This mixing process is controlled by injection and spray propagations. For this reason, several work has been done to further characterizing the impact of different injection parameters on spray development [2-3] and to create correlations between near-nozzle flow behavior and diesel engine performance which increase the ability of designing more efficient diesel engines. Detailed experimental data not only lead to further understanding of the spray behavior from the injector, but also provide valuable knowledge to enhance computational modelling capabilities.

Over the past few years, different optical diagnostics have been widely developed to characterize and optimize diesel spray [4] (such as Laser induced fluorescence [5], Spontaneous Raman scattering [6-7], Mie scattering [8], PIV [9], DBI, etc...). However, due to the visible light scattering, which is strongly refracted from droplets in the dense near nozzle area, the analysis of the spray dense core by these techniques has been limited. Since 2000, the absorption of X-ray, generated by Argonne's Advanced Photon Source has been developed to understand the 
near-nozzle spray better [9-12]. The X-ray radiography technique is perhaps one of few methods able to measure the liquid mass distributions in otherwise complex sprays [7-9] permitting analyses that cannot be performed using optical spray diagnostics. This greatly simplifies the analysis as the attenuation signal can be related to the liquid mass density in the path of the X-rays with minimal sensitivity to the droplet size. Recently, Xray micro-source has been used for the estimation of the temporal-averaged vapour volume fraction within high-speed cavitating flow orifices [17].

In general, three common anode elements iron, copper and tungsten, can be used to produce X-ray photons for spray diagnostics. The higher $\mathrm{X}$-ray fluxes are obtained with tungsten anodes but the X-ray spectrum is composed of several characteristic $L$ lines which is not a very favorable situation for spray density calculation, ideally achievable with a monochromatic radiation. Iron electrodes exhibit the lower energy photons in the $\mathrm{K}$ lines around $6.4 \mathrm{keV}$ but, in this case, the X-ray flux is much lower and the sputtering of the anode during electron bombardment is to high impeding to operate this material in repetitive experiments over few hundreds of shots. View that the $\mathrm{X}$ ray propagation path from the $\mathrm{X}$-ray source to the CCD camera, the $\mathrm{X}$-ray source used in this work is a table top micro focus X-ray tube equipped with a copper anode [14] to get the best compromise between the X-ray flux and the contrast between the jet and the chamber absorption with high dynamic. The purpose of this paper is to present the benefits and limitations of using the X-ray source and to suggest some recommendations for improving performance.

The technique was applied in the case of Cerium (Ce) doped dodecane sprays through micrometric nozzles (hole diameter $90 \mu \mathrm{m}$ ) in NOSE at HPHT. Cerium is used for its strong impact on the X-ray diagnostics due to the strong photon absorption of $\mathrm{Ce}$ at relatively low X-ray energy and this additive is used in engine technology for the regeneration of diesel filters issues. This additive has been used in synchrotron based diagnostics which have been performed with energy beams around $8 \mathrm{keV}$ [15-17]. The experiments were conducted for different pressures and different concentrations of $\mathrm{Ce}$ in order to visualize the jet of dodecane with the polychromatic X-ray micro source with $\mathrm{Cu}$ anode. Experimental radiography of dodecane spray expansion, cone angle and density measurements will be performed by several shots X-ray measurement and also compared with the average measurement over a large number of shots which enhance the quality of the signal and allow a more detailed analysis. The spray cone angle is determined from the width of the spray at several axial sections. Absorption and density measurement obtained from $5 \mathrm{~ms}$ injection of $20 \%$ Ce doped n-dodecane spray are presented. Finally, the vertical binning being key point of $\mathrm{X}$-ray measurement to achieve a good value of signal to noise ratio is analysed.

\section{Material and methods}

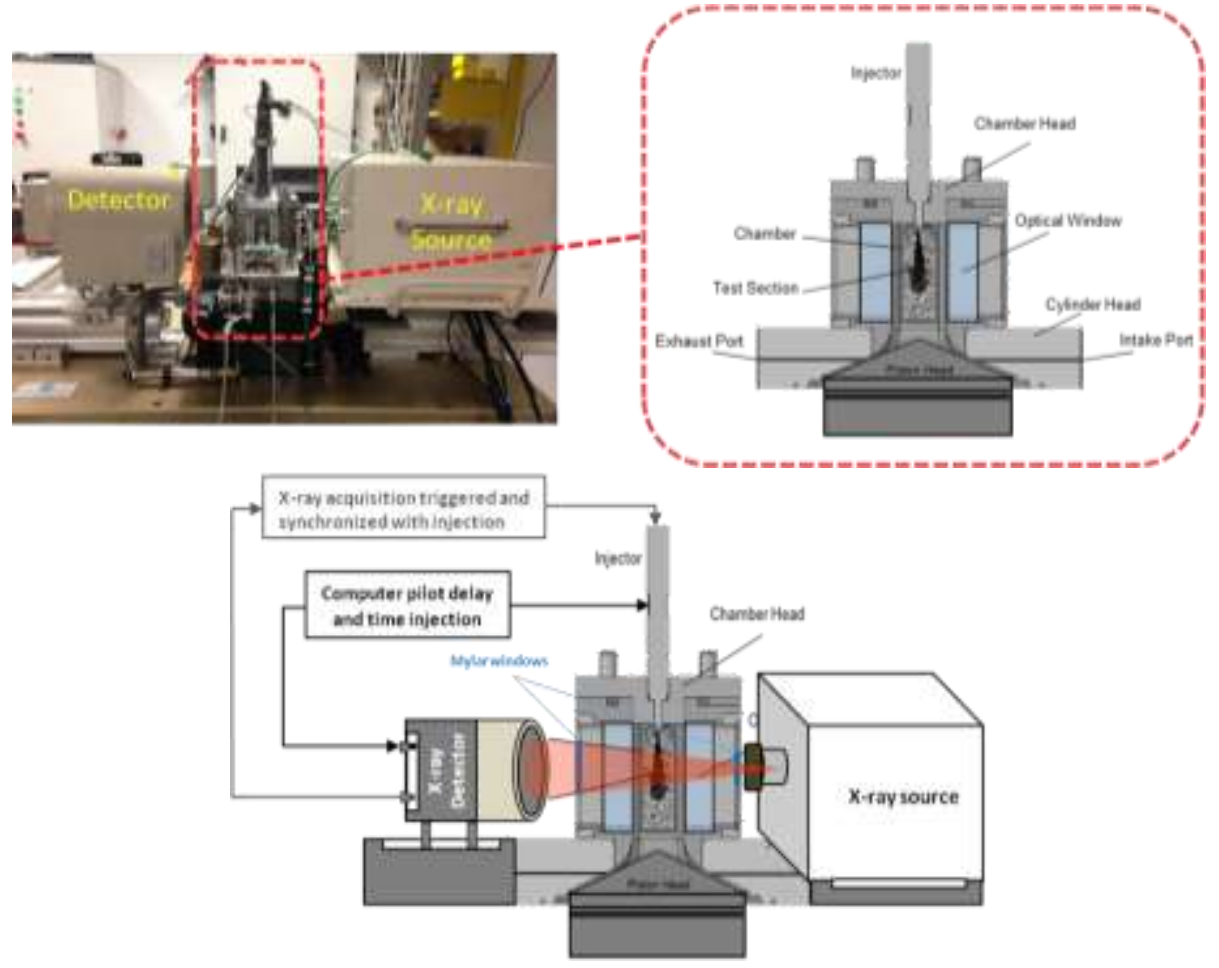

Figure 1: Photo shows the X-ray micro-source and detector and that on the right details the black spray chamber. At the bottom, a schematic of the experimental setup is shown thus the radiography device associated and synchronized with the injection system of spray chamber. 
The layout of the experimental set-up is shown in Figure 1. It composed from four main subassemblies: a high pressure and high temperature chamber, micro X-ray source, an X-ray CCD camera and a pilot for the triggering and synchronization of the X-ray source shots and the needle injector control. The experimental set-up about the new combustion chamber based on concept of rapid cycling machine called "New One Shot Engine (NOSE) developed to study the diesel spray has been described in detail elsewhere [1] and only a short summary will be given here. NOSE is based on the use of one-cylinder low-speed diesel engine of 18 horse power HP at $750 \mathrm{rpm}$. This cylinder has $155 \mathrm{~mm}$ bore diameter and a $177.8 \mathrm{~mm}$ stroke. The original cylinder head was replaced by a dedicated chamber, designed by extending the combustion chamber for supporting optical technique measurements.

For X-ray diagnostic, the transmission through the window depends on its thickness and the material it is made of. The X-ray beam passes through a pressurized spray chamber with $\mathrm{X}$-ray rectangular windows $(25 \mathrm{~mm}$ wide, $80 \mathrm{~mm}$ high) where rectangular slits equipped with $125 \mu \mathrm{m}$ thick Mylar films, with high X-ray transmission, have been used as entrance and exit windows along the $\mathrm{X}$-ray propagation path from the $\mathrm{X}$-ray source to the $\mathrm{X}$-ray detector. The layer of Mylar will slightly decrease (a few percent) the transmission of the X-rays. Other advantages of Mylar is its resistance to high pressure and it can also support more than hundreds of cycles. After the beam passes through the spray chamber, the X-ray radiographies are acquired using X-ray CCD camera. This camera offers approximately high quantum efficiency with 12 bits of dynamic range. The detector is optimized for low energy $X-$ rays $(20 \mathrm{KeV})$ using high contrast $X$-ray image intensifier (4 inch). X-rays are converted in visible light through an efficient scintillator and this emission is then detected with $1920 \times 1440$ pixels CMOS image sensor and $0.5 \mathrm{~mm}$ of Beryllium as input window. The camera is placed $25 \mathrm{~cm}$ from the high pressure chamber giving a magnification equal to 1. The X-ray diagnostic is triggered and synchronized with zero delay between time of acquisition and time of injection. The X-ray diagnostics of liquid jet depends on strong absorption of the X-ray beam by the liquid fuel. This is essential at high ambient density levels, since the ambient gas in the chamber can absorb a significant amount of the x-ray intensity. To enhance the x-ray absorption coefficient of dodecane, a cerium fuel additive has been added. The properties of the fuel are listed in Table 1.

Table 1. Fuel Physical properties

\begin{tabular}{c|cc}
\hline \hline Properties & n-dodecane & DPX 9 \\
\hline \hline Density $\left(\mathrm{kg} \cdot \mathrm{m}^{-3}\right)$ & 753 & 1107 \\
Dynamic viscosity $(\mathrm{mPa}$.s $)$ & 0.97954 & 4.1786 \\
kinematic viscosity $\left(\mathrm{mm}^{2} . \mathrm{s}^{-1}\right)$ & 1.3335 & 3.7756
\end{tabular}

The average energy measurement of the micro X-ray source used in this work was determined. This quantity is relevant for the spray density calculation. For this purpose, X-ray transmission of increasing number of Kapton® $\left(\mathrm{C}_{12} \mathrm{H}_{22} \mathrm{O}_{2} \mathrm{~N}_{2}\right)$ foils each having a thickness of $50 \mu \mathrm{m}$ with a $1.42 \mathrm{g.cm}{ }^{-3}$ density are performed for calibration, knowing that the $\mathrm{x}$-ray absorption of this material is well known. The measurement of these test objects transmission was realized in the same configuration of that used later for spray diagnostics with rigorous Signal-to-Noise ratio study.

Table 2. Description of ECN spray $A$ boundary conditions and X-ray radiography test conditions

\begin{tabular}{c|c}
\hline \hline Parameter & Dodecane \\
\hline Injector body type & Bosch CR 2.16 \\
Nozzle type & Single hole, axially oriented \\
Nozzle outlet diameter $(\mu \mathrm{m})$ & 90 \\
Fill gas & Nitrogen $\left(\mathrm{N}_{2}\right)$ \\
Ambient gas temperature $(\mathrm{K})$ & 900 \\
Ambient gas pressure $(\mathrm{MPa})$ & 6.0 \\
Ambient gas density $\left(\mathrm{kg} \cdot \mathrm{m}^{-3}\right)$ & 22.8 \\
Fuel & n-dodecane \\
Fuel injection pressure $(\mathrm{MPa})$ & 150 \\
Fuel temperature at nozzle $(\mathrm{K})$ & 363 \\
Injection duration $(\mathrm{ms})$ & 5
\end{tabular}

The radiography measurements fundamentally measure the path-length-integrated amount of liquid in the $x$-ray beam. At each measurement location, the projected mass per unit area along the beam pass $\Delta M$ is related to the measured transmission by the Lambert-Beer law:

$$
\Delta M=\int \rho d z=\frac{-1}{\mu} \log \left(\frac{I_{(t)}}{I_{0}}\right)
$$


In this equation, $I_{(t)}$ and $l_{0}$ are the transmitted and incident beam intensities (i.e. during and before the injection), $\mu$ is the absorption coefficient (per mass/area) and $\rho$ the local fuel density in the spray, which will generally be lower than the density of undisturbed liquid.

\section{Results and discussion}

\section{Example of typical Data}

Data were obtained for two levels of pressure (1bar and 60 bars). The impact of the added amount of doping agent (Eolys Rhodia DPX 9) on the physical characteristics of the spray is illustrated in Figure 2. Comparisons between the diffused back illumination images acquired from n-dodecane spray without DPX 9 containing Ce (Figure 2 a) and these obtained from n-dodecane spray with $20 \%$ of Ce (Figure 2 b) showing clearly that liquid penetration length is higher when DPX is present. The current data also show that for $20 \%$ of DPX mixed with n-dodecane, the physical characteristics of $n$-dodecane spray and its behavior show several significant differences from the $n$ dodecane spray without DPX (i.e. viscosity, density). Moreover, the data presents different rate of evaporation and it is clearly observed that there is no possible determination of liquid length of the spray obtained with $20 \%$ of DPX, as seen by the shadow and the larger dark area in Figure $2 \mathrm{~b}$ showing the unevaporated part of the fuel. Thus measurements with lower concentrations of dopant under similar boundary and injection conditions were performed in order to determine the lowest concentration of dopant making it possible to keep similar physical properties of the spray while enabling visualization of the jet by X-rays. As illustrated in Figure 2 when the percentage of Ce decreases, the DPX 9 starts to evaporate efficiently. For $2.5 \%$ of $\mathrm{Ce}$, appearance of two regions where we can observe that the darker region decreases to $10.5 \mathrm{~mm}$ and for $0.25 \%$, an important evaporation of DPX is obtained. Liquid length around $10.5 \mathrm{~mm}$ is achieved from the Figure 2 (f).
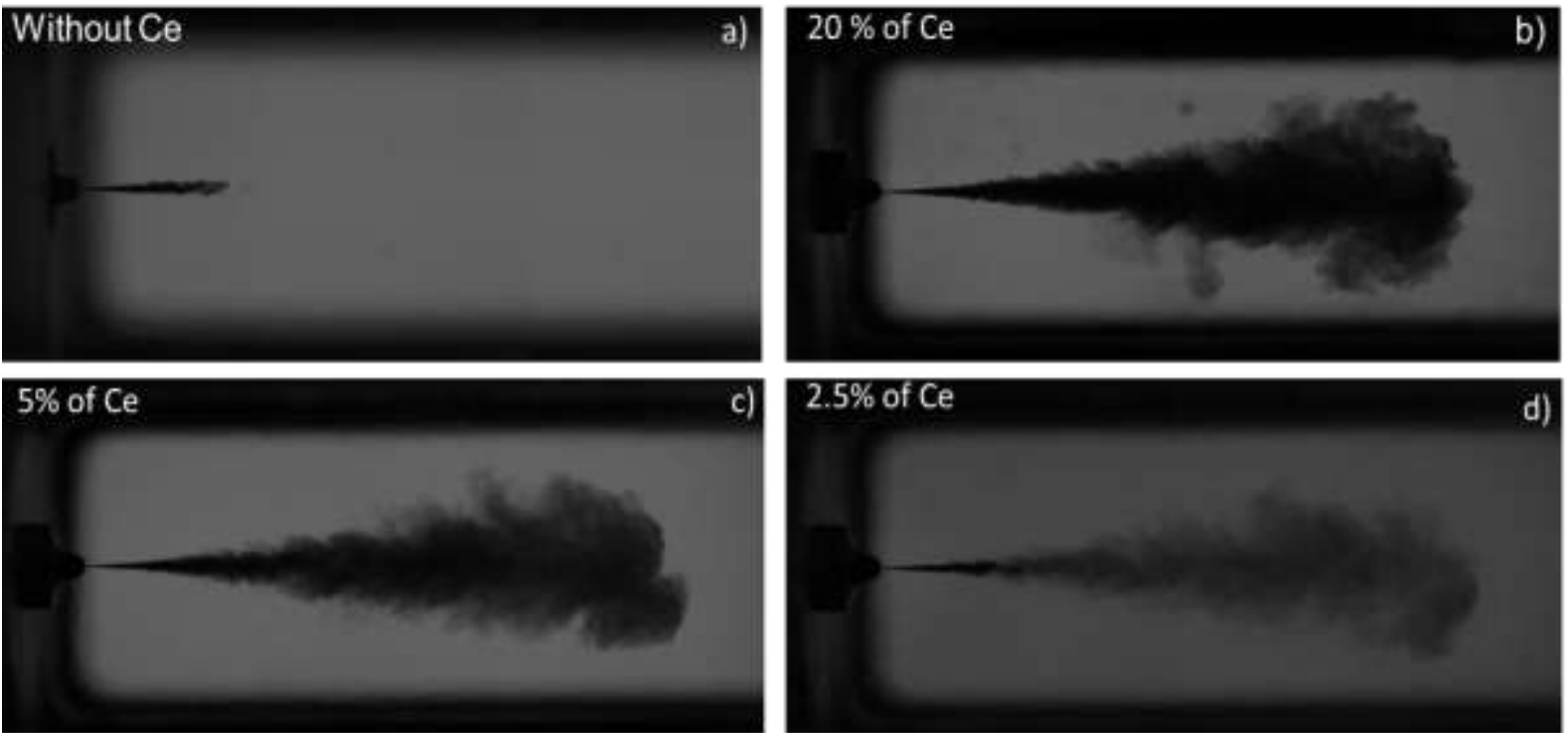

\section{$1.25 \%$ of $\mathrm{Ce}$}

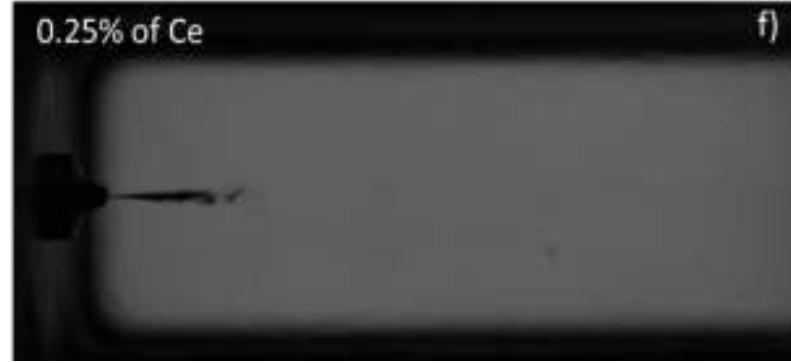

Figure 2: Examples of Diffused Back Illumination instantaneous image of the spray at 60 bar $900 \mathrm{~K}$ (a) dodecane without DPX (b) dodecane doped with $20 \%$ of $\mathrm{Ce}$ (c) dodecane doped with $5 \%$ of $\mathrm{Ce}$ (d) dodecane doped with $2.5 \%$ of $\mathrm{Ce}$ (e) dodecane doped with $1.25 \%$ of $\mathrm{Ce}(\mathrm{f})$ dodecane doped with $0.25 \%$ of $\mathrm{Ce}$. 


\section{Spatial resolution}

The resolution of the full X-ray radiography setup was first calculated from the analysis of the grey level profiles of $1 \mathrm{~mm}$ thick lead and air line pairs with a number of line pairs per $\mathrm{mm}$ extracted from the radiograph illustrated in Figure $3 \mathrm{a}$ ). The calculation of the modulation transfer function involving the ratio of the peak-to-valley grey level amplitude to the maximum grey level value amplitude, for the different spatial frequencies, associated with the number of line pairs per $\mathrm{mm}$, together with the calculation of the signal to noise ratio.

Figure 3 presents the grey level profiles obtained in the geometrical configuration of this experiment averaging over 100 shots and showing that significant contrasts are obtained for patterns as small as $100 \mu \mathrm{m}$ which is appropriate for this work. The estimated spatial resolution of the $\mathrm{X}$ ray setup is around $120 \mu \mathrm{m}$.
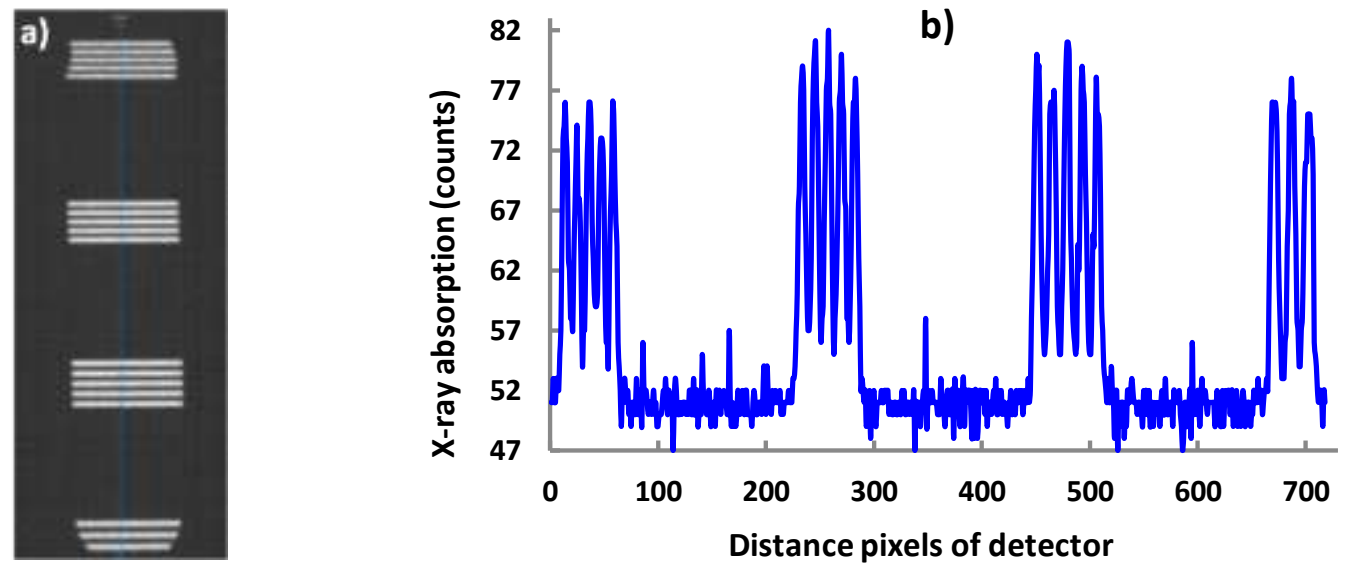

Figure 3: a) Radiograph of calibrated line pair pattern with detector at $25 \mathrm{~cm}$ from injector. b) Grey level profiles extracted from radiograph (a). From left to right, the pattern consists in $4.55,4,3.15$ and 3.55 , line pairs per $\mathrm{mm}$.
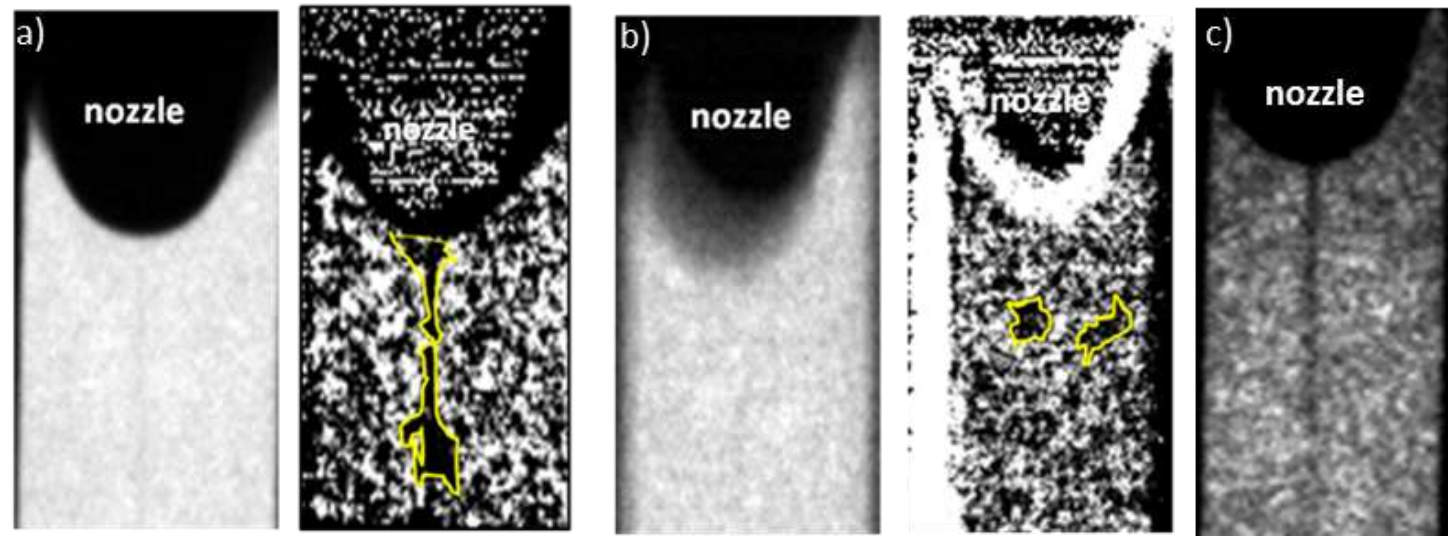

Figure 4: $20 \%$ Ce doped $\mathrm{n}$-dodecane at $900 \mathrm{~K}$ sprays radiographs, (a), (b) radiograph at ambient pressure and 60 bars, respectively, left: transmitted beam and right: absorption, (c) $40 \% \mathrm{Ce}$ doped $\mathrm{n}$-dodecane at $850 \mathrm{~K}$ and 20 bars sprays radiographs

Radiography data was obtained from averaging 10 shots from the X-ray measurements. A slight asymmetry in the flow is evident, even though the nozzle geometry is normally axisymmetric. The measurements were realized over several averaged X-ray shots in the same configuration of that used later for diagnostic of $20 \%$ Ce doped $n$ dodecane spray (894 Kg.m ${ }^{-3}$ at $300 \mathrm{~K}$ and ambient conditions). The X-ray CCD camera was set $25 \mathrm{~cm}$ from the spray chamber integrate the filtering of ambient air, high pressure chamber and Mylar window. In these experimental conditions the mean X-ray energy was determined to be of $8 \mathrm{KeV} \pm 0.3$. The injection duration and X-ray camera duration were both $5 \mathrm{~ms}$ close to the emission of the characteristic Ka copper line of $\mathrm{X}$-ray micro source. As shown in Figure 4, radiography collected at 1 bar and 60 bar chamber pressure shows the absorption by the jet near to the nozzle. Notable observation from the radiographs (a) and (c), that spray present a cone angle focused near of nozzle and the measurements from radiography can be based on the behavior of the dense core of the spray, which contains most of the spray mass. Examples of Ce doped dodecane sprays line profile and their radiographies at different pressure are shown in Figure 5. 

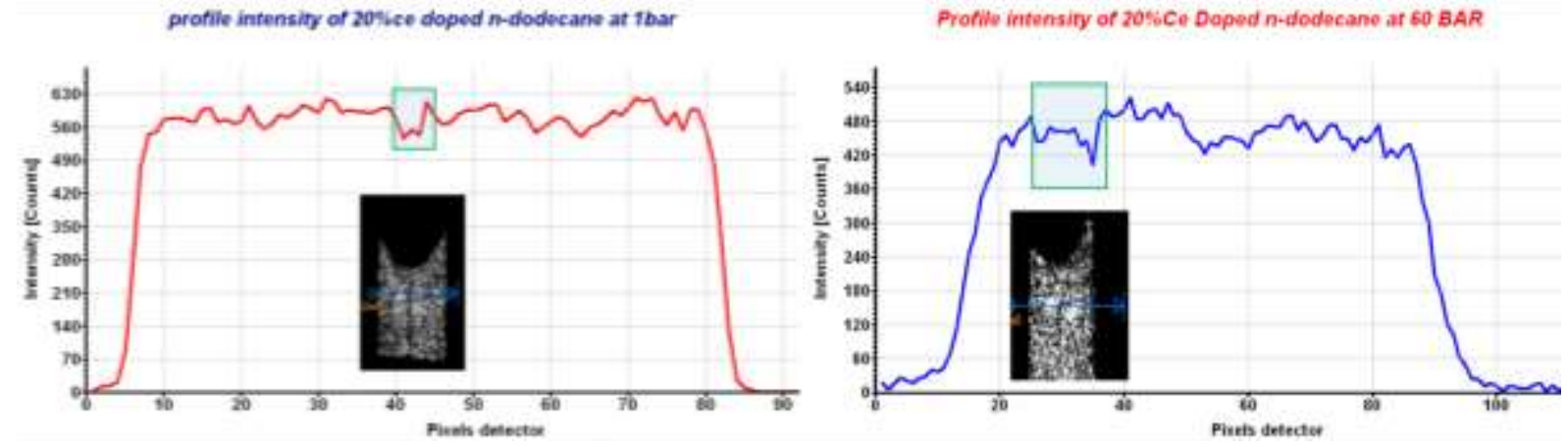

Figure 5: Ce doped dodecane sprays line profile and their radiographies (right) radiographies at 1 bar of pressure (left) radiographies at pressure of 60 bars.

Determining the spray cone angle is to define a width of the spray at several axial sections. In this study, the fullwidth, half-maximum (FWHM) is determined by fitting a transmitted or absorption signal with a Gaussian function. Figure 6 indicates that the FWHM values near the nozzle are quite similar for both operating conditions and the FWHM increases significantly with axial distance for the nozzle.

From the limited quality radiograph with this percentage of $\mathrm{Ce}$, the spray propagation occurs in a very stable approach from one injection event to another due to similar result obtained along the line where the continuous jet is obtained over a straight vertical propagation. The full angle of aperture deduced from the measurement of the ratio of the radial extension to the downstream propagation length has a constant value of about $5^{\circ}$ with no significant evidence for the presence of dodecane out of this cone. The maximum density inferred from the ratio grey level value measured in and out of the jet and accounting for an average X-ray energy of $8.0 \pm 0.3 \mathrm{keV}$ and the dodecane $X$ ray absorption cross section for this $X$-ray energy, is of about $0.6 \mathrm{~g} . \mathrm{cm}^{-3}$.
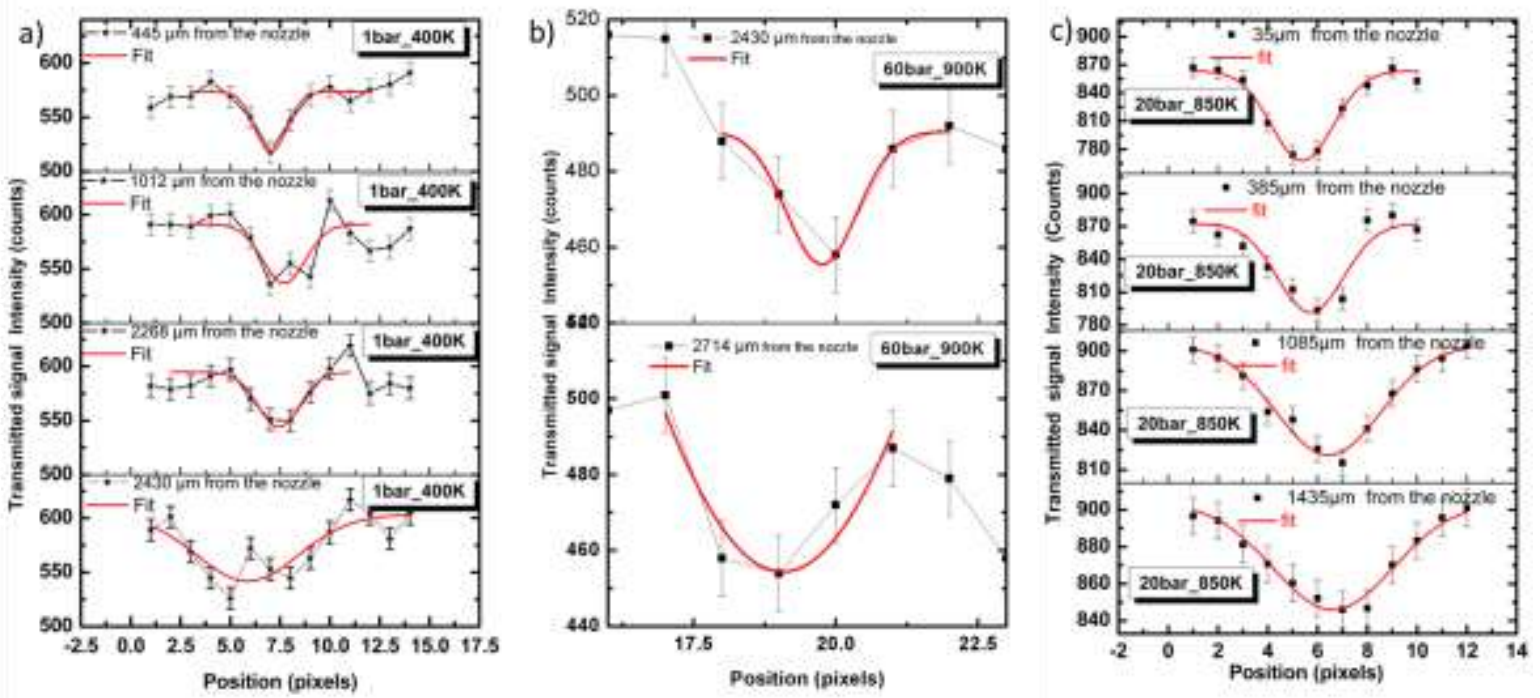

Figure 6: Fits and lines profiles of transmitted signals of $20 \%$ Ce doped dodecane sprays at several axial positions from the nozzle. (a) 1 bar of pressure, (b) radiograph at pressure of 60 bars, (c) radiograph at pressure of 20 bars.

Table 3 shows the density measurement obtained from 5 ms injection of Ce doped n-dodecane spray calculated from radiographs at different position of spray from the nozzle. Reminding that the density of the mixing of $20 \% \mathrm{Ce}$ doped $\mathrm{n}$-dodecane spray is $894 \mathrm{Kg} \cdot \mathrm{m}^{-3}$ at $300 \mathrm{~K}$ and ambient conditions. During the propagation of the spray, the density decreases due to the air entrainment. A considerable increasing of the density is obtained at high pressure (60 bar) and high temperature $(900 \mathrm{k}$ ). Under this condition, the fuel evaporates. During the vaporization of dodecane the cerium level increases causing the increasing of the density. The uncertainty in the density determination is calculated by determining the uncertainty in measuring the absorption coefficient and the photon shot noise, which follows a Poisson distribution. By propagating the error through the logarithm of equation 1 , the resulting uncertainty in density is less than $8 \%$. 
Table 3. Parameters of $5 \mathrm{~ms}$ of injection duration of $20 \%$ and $40 \%$ of Ce doped $\mathrm{n}$-dodecane spray calculated from radiographs (presented in Figure 4) at different position of spray from the nozzle.

\begin{tabular}{c|ccc}
\hline \hline $\begin{array}{c}\text { Pressure in the } \\
\text { chamber }\end{array}$ & $\begin{array}{c}\text { Position from the } \\
\text { nozzle }(\mu \mathrm{m})\end{array}$ & FWHM & Density $\left(\mathrm{kg} / \mathrm{m}^{3}\right)$ \\
\hline \hline & 445 & $2.103 \pm 9.5 \%$ & $875 \pm 1.1 \%$ \\
1 bar & 1012 & $2.477 \pm 6 \%$ & $870 \pm 1.1 \%$ \\
$(20 \%$ of Ce) & 2268 & $2.536 \pm 8.2 \%$ & $868 \pm 1.2 \%$ \\
& 2430 & $6.047 \pm 5.8 \%$ & $852 \pm 3.5 \%$ \\
& 35 & $3.124 \pm 6.7 \%$ & $960 \pm 2 \%$ \\
20 bar & 385 & $3.398 \pm 23.8 \%$ & $958 \pm 4.8 \%$ \\
$(40 \%$ of $\mathrm{Ce})$ & 1085 & $4.968 \pm 9 \%$ & $957 \pm 4.2 \%$ \\
& 1435 & $6.094 \pm 13.9 \%$ & $952 \pm 2.1 \%$ \\
60 bar & 2430 & $1.463 \pm 34.1 \%$ & $950 \pm 6.2 \%$ \\
$(20 \%$ of $\mathrm{Ce})$ & 2714 & $4.432 \pm 7.8 \%$ & $964 \pm 7.1 \%$
\end{tabular}

\section{Signal to Noise Ratio (SNR)}

To quantify the capacity of the actual setup with micro X-ray source to detect the cerium doped dodecane sprays through micrometric nozzles in a HPHT injection chamber, SNR analysis was also performed on single-shot $X$ ray measurement where we make binning along one, and several line profiles, respectively. Each line profile of the detector correspond to a vertical resolution of $30 \mu \mathrm{m}$. So that considering the spatial resolution of the diagnostics in the present experimental setup, pixel binning to enhance signal to noise ratio is not a severe limitation.

The SNR values obtained from the X-ray measurement are defined as the ratio of mean peak intensity of the minima subtracted from the mean environment intensity to the root-mean-square ( $\mathrm{rms}$ ) fluctuations of the pixel signal in the image. The radiograph images from the $X$ ray source were dark-current subtracted.

$S N R=\frac{\mid I_{\text {hole }}-\text { Mean of environment Intensity } \mid}{\sigma_{\text {fluctuation of pixels signal }}}$
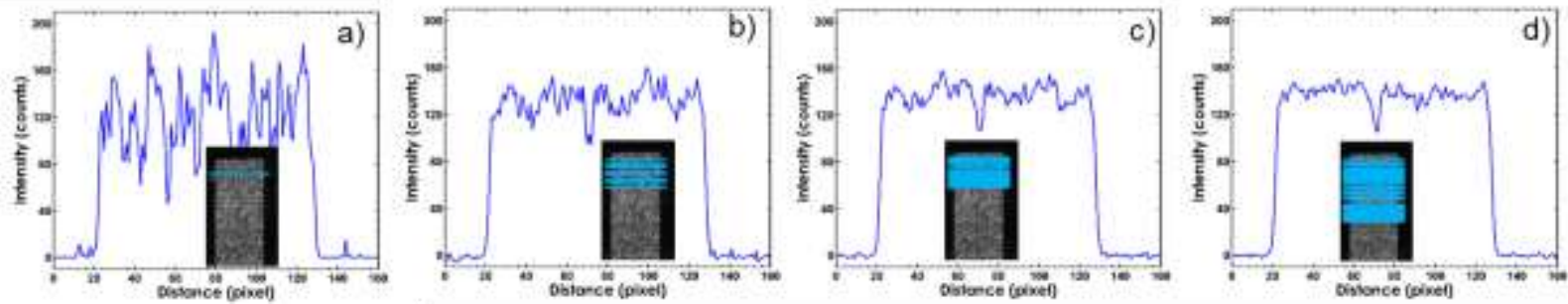

Figure 7: Single-shot X-ray Ce doped dodecane sprays profile and their radiographies at 1 bar and 300K by binning over (a) 1 line (b) 10 lines (c) 50 lines (d) 100 lines.

Table 4. SNR obtained from radiographies at 1 bar by binning over different number of lines.

\begin{tabular}{c|cccc}
\hline \hline Number of lines & 1 & 10 & 50 & 100 \\
\hline \hline SNR & 0.8 & 2.3 & 3.7 & 4.2
\end{tabular}

Due to the low absorption of a few percent of the dodecane sprays, injection events require to be averaged over a few hundred of X-ray shots to get sufficient SNR from radiographs. If we increase the number of shots the SNR for $20 \%$ dopant is improved. In our experiment conditions, good compromise to achieve a reasonable SNR is 10 shots for 1 bar and 100 shots for 60 bars. However, as we can see in the single shot $X$ ray measurement applied at ambient condition to Ce doped dodecane (Figure 7), signal of the jet is completely drowned inside the backgroundnoise. When binning over large number of line increases, a considerable reduction of RMS is obtained leading to increase the SNR and then the absorption of jet is clearly seen. This analysis suggests to reduce the percentage of dopant and to make vertical binning on X-ray radiography. An improvement in SNR is clearly observed when vertical binning is performed and the presence of the jet of dodecane can be clearly detected.

\section{Conclusions}

To the best of our knowledge, this is the first time that X-ray radiography of a dodecane jet at high pressure and high temperature have been obtained in spray A conditions using new one shot engine. X-ray radiography has demonstrated its potential as a useful quantitative diagnostic for studying dense fuel sprays. From the various 
studies carried out to study the effect of DPX dopant on the physical characteristics of dodecane spray, it has been shown that the behavior of the spray is completely different when high concentration of dopant is mixed with the dodecane. Liquid penetration length was determined when decreasing the Ce dopant concentration in dodecane till $1.25 \%$. Further analysis suggested to reduce the percentage of dopant and to make vertical binning on $\mathrm{X}$-ray radiography, for which improvement in signal to noise-ratio was clearly observed and the presence of the jet of dodecane can be detected. The full angle of aperture deduced from the measurement is around $5^{\circ}$. Density and absorption measurement obtained from $5 \mathrm{~ms}$ injection of $20 \%$ Ce doped n-dodecane spray at $900 \mathrm{~K}$ are around $950 \mathrm{~kg} / \mathrm{m}^{3}$. First experiments show that measurement output is a compromise between, on the one hand, the percentage of dopant for which the physical characteristics and the behavior of the spray do not change, and on the other hand the visualization of the jet by X-ray.

\section{Acknowledgements}

This work is supported by ANR Research National Agency (ECN-France project). I.C. is supported by ANR PLANEX ANR-11-EQPX-0036-01. The authors would like to thank Thierry Seguelong for DPX9 supply and Gilles Bruneaux for scientific discussions.

\section{References}

[1] O. Nilaphai et al., "New high pressure and high temperature chamber for Diesel spray characterization," in ILASS - Europe 2016, 27th Annual Conference on Liquid Atomization and Spray Systems, 4-7 September, 2016, pp. 1-10.

[2] E. Giannadakis, M. Gavaises, and C. Arcoumanis, "Modelling of cavitation in diesel injector nozzles," J. Fluid Mech., vol. 616, no. September, p. 153, 2008.

[3] S. Tonini, M. Gavaises, C. Arcoumanis, and a. Theodorakakos, "Prediction of Liquid and Vapor Penetration of High Pressure Diesel Sprays," SAE Tech. Pap., vol. 2006, no. 724, 2006.

[4] D. L. Siebers, "Liquid-Phase Fuel Penetration in Diesel Sprays." SAE International , 1998.

[5] M. Wolff, a Delconte, F. Schmidt, P. Gucher, and F. Lemoine, "High-pressure Diesel spray temperature measurements using two-colour laser-induced fluorescence," Meas. Sci. Technol., vol. 18, no. 3, pp. 697706, 2007.

[6] H. Ajrouche, A. Lo, P. Vervisch, and A. Cessou, "Detector assessment for 1D single-shot spontaneous Raman scattering for temperature and multi-species measurements in flames," in 18th International Symposium on Applications of Laser Techniques to Fluid Mechanics, 04-07 July, 2016.

[7] H. Ajrouche, A. Lo, P. Vervisch, and A. Cessou, "Assessment of a fast electro-optical shutter for 1D Spontaneous Raman Scattering in flames," Meas. Sci. Technol., vol. 26, no. 7, p. 075501 (9pp), 2015.

[8] A. Adam, P. Leick, G. Bittlinger, and C. Schulz, "Visualization of the evaporation of a diesel spray using combined Mie and Rayleigh scattering techniques," Exp. Fluids, vol. 47, no. 3, pp. 439-449, 2009.

[9] Z.-M. Cao, K. Nishino, S. Mizuno, and K. Torii, "PIV measurement of internal structure of diesel fuel spray," Exp. Fluids, vol. 29, no. 7, pp. S211-S219, 2000.

[10] B. R. Halls, T. J. Heindel, A. L. Kastengren, and T. R. Meyer, "Evaluation of X-ray sources for quantitative two- and three-dimensional imaging of liquid mass distribution in atomizing sprays," Int. J. Multiph. Flow, vol. 59, pp. 113-120, 2014.

[11] P. Leick, T. Riedel, G. Bittlinger, C. F. Powell, A. L. Kastengren, and J. Wang, "X-ray measurements of the mass distribution in the dense primary break-up region of the spray from a standard multi-hole common-rail diesel injection system," Proc. ILASS - Eur. Meet., pp. 1-6, 2007.

[12] D. J. Duke, A. B. Swantek, A. L. Kastengren, and C. F. Powell, "X-ray Diagnostics for Cavitating Nozzle Flow," J. Phys. Conf. Ser., vol. 656, p. 12110, 2015.

[13] D. J. Duke et al., "X-ray radiography of cavitation in a beryllium alloy nozzle," Int. J. Engine Res., pp. 113, 2016

[14] E. Robert, S. Dozias, C. Cachoncinlle, and J. M. Pouvesle, "Flash X-ray diagnostics of dodecane injection through micrometric nozzle."

[15] a. I. Ramírez et al., "Quantitative X-ray measurements of high-pressure fuel sprays from a production heavy duty diesel injector," Exp. Fluids, vol. 47, no. 1, pp. 119-134, 2009.

[16] A. L. Kastengren, C. F. Powell, Y. Wang, K.-S. Im, and J. Wang, "X-Ray Radiography Measurements of Diesel Spray Structure At Engine-Like Ambient Density," At. Sprays, vol. 19, no. 11, pp. 1031-1044, 2009.

[17] M. Lorenzi, N. Mitroglou, M. Santini, and M. Gavaises, "Novel experimental technique for 3D investigation of high-speed cavitating diesel fuel flows by X-ray micro computed tomography," Rev. Sci. Instrum., vol. 88, p. 33706, 2017.

[18] A. L. Kastengren et al., "Axial Development of Diesel Sprays at Varying Ambient Density Argonne National Laboratory Advanced Photon Source Argonne National Laboratory," in ILASS Americas, 22nd Annual Conference on Liquid Atomization and Spray Systems, Cincinnati, OH, 2010, no. May.

[19] A. L. Kastengren, C. F. Powell, K.-S. Im, Y.-J. Wang, and J. Wang, "Measurement of Biodiesel Blend and Conventional Diesel Spray Structure Using X-Ray Radiography," J. Eng. Gas Turbines Power, vol. 131, no. 6, pp. 62802-62807, Jul. 2009. 